\title{
Assessment of ecosystem health and ecotoxicology through chemical analysis and modeling
}

\author{
Ji-Dong Gu
}

Accepted: 27 January 2014/Published online: 22 March 2014

(C) Springer Science+Business Media New York 2014

The industrialization and urbanization in China over the past 30 years have resulted in serious deterioration and contamination of the natural ecosystems in terms of air, soil, water and also the biota as evidenced by chemical and toxicological data reported widely (Ford and Cheng 2009; Ford et al. 2011; Gu and Wang 2012, 2013; Zhao et al. 2013). As chemical analysis can show the concentrations of specific contaminants at the time and locations of sampling, it serves as a direct indication on the extent of contamination, but it also has its own limitations by the entities of the sampled and the analytical methods used. Such data are only relevant to the specific compartments of the ecological niche under the specific conditions at the time of sampling and the methods used (Zhao et al. 2012a, b). Collection of environmental data that can yield historical events is hardly possible with routine chemical analysis alone except for a few cases, e.g., lead isotopic ratio for the sources of the contamination in sediment cores and nitrogen isotope ratio for the sources of pollution. As such, alternative approaches in understanding the environmental impact from pollution and toxic chemicals can be ecological based by using indicators that can stand the test of time to reflect the historical events of the past or pollution. In general, ecological investigations have not been given the importance and uniqueness as they deserve mainly due to the high variability and also the long duration of the study for collection of meaningful data to reach a more convincing conclusion (Shen et al. 2010). However, it is undeniable that ecological analysis coupling with chemical data can provide more insights to the environmental status

J.-D. Gu ( $\square)$

School of Biological Sciences, The University of Hong Kong, Pokfulam Road, Hong Kong, People's Republic of China e-mail: jdgu@hku.hk of the ecosystems and the changes that have been taking place. In a similar but different approach, microbial community structure composition of selective biochemical process can be used as reliable environmental quality indicators, anammox bacteria as one has been proposed as selective species of this group are only detected in contaminated environments while others are only in pristine ecosystems (Cao et al. 2011, 2012, 2013; Li et al. 2011a, b). Since PCR-based amplification of specific DNA templates extracted from sediments/soils is highly specific and sensitive, this approach has been successful in confirming the anthropogenic pollution sources. All of these new advances are important in further scientific understanding of the living environment and in preventing against detrimental changes due to anthropogenic impacts.

We believe that the research field of ecotoxicology can be advanced by more in-depth research and fundamental investigations of environmental chemistry, ecotoxicology and environmental/pollution toxicology, applied biology and molecular biology to provide the essential basic information and key data for a better understanding of the environmental issues and also protection of the environment. It is non-disputable that many scientists in China have actively engaged in research on pollution sources, types of the pollutants, toxic effects of chemicals on target and non-target organisms at a wide range of response levels including molecular, enzymatic, and organismic levels, especially many studies carried out in laboratory under simulated and controlled conditions (Han et al. 2011; Wu et al. 2009; Zhao et al. 2009, 2013). The information from such hypothetical studies must serve the needs for problem solving in the real world, which is community and ecosystem based. Here an integration of studies on ecosystem ecology and computer modeling with toxicology and analytical chemistry has been collected from selective papers 
of talks presented at the 4th International Symposium on Environmental Health and Pollution Control (4-ISEHPC) held on September 23-25 in Harbin and continued on September 26-28, 2012 in Beijing, PR China to make these results in a permanent form for scientific community worldwide.

It was our primary purposes initially in organizing this series of symposia over the last 10 years to gather scientific data from local scientists to discuss their on-going research projects, communicate the latest research results and effectively disseminate such information at each symposium so that future coherent research projects could be formulated and carried out for a better, systematic and common understanding of the magnitude of environmental problems, basic mechanisms and possible mitigation strategies. By doing so, research projects in planning phase by graduate student and post-docs can benefit from such information exchanges to advance the better understanding of the scientific questions involved. At the same time, it was also our hope that legislatures and governing bodies of government would benefit from such information and to implement science-based policy with the scientific data available as a basis. It is clearly important that multi-disciplinary interactions are necessary and essential not only to better our understanding and effective planning of research projects in ecotoxicology, but also to implement any remedial measures to deal with the environmental problems facing not only China but particularly the developing countries and emerging powers in the world in the near future (Ford et al. 2011; Gu and Wang 2012, 2013; Zhao et al. 2013). The Ministry of Environmental Protection of PR China reported the negative changes of the physical, chemical and biological characteristics of ecosystems in the annual status reports openly recognizing the aggravated environmental condition. The elucidation of processes and mechanisms involved is the primary responsibility of scientists so that administrative and management plans can be formed to deal with such condition most effectively.

This symposium series went back to 2005, at the time Prof. Shupei Cheng at the School of the Environment, Nanjing University, PR China identified the importance of research on relationship between pollution and health. As a result, the First International Symposium on Environmental Health and Pollution Control (1-ISEHPC) was held at Nanjing University in 2006. Unfortunately, I had to cancel my plan to attend the inauguration symposium due to an unexpected event preventing me from witness this event personally. After a year, he informed me about his planning to hold the Second ISEHPC in 2008 in Nanjing again and I responded that some key outcomes needed to be identified to be beneficial to the graduate students, post-docs and young scientists all together to elevate their research skills, in particular on scientific writing for academic publications which are heavily weighed toward English language than the native Chinese. Bearing this in mind, a Special Issue on EHPC was in our plan and selective papers were published the first time in Ecotoxicology in 2009 as a Special Issue to documents the research activities and the pollution problems in China (Ford and Cheng 2009). Subsequently, the 3rd ISEHPC was held in 2010 in both Nanjing and Beijing to cover a much diverse and wider audience and another SI was published in Ecotoxicology in 2011 (Ford et al. 2011). As the community of concerned scientists was being more aware of the focused research activities on the identified area, ecologists equipped with modeling capability also actively participated in the 3rd ISEHPC, the 4th ISEHPC was held in both Harbin and Beijing in 2012 and the outcomes of this symposium are presented here. Through the past more than a dozen of years on research collaboration between Prof. Cheng and I, we had produced joint research outputs as published papers and patents and, more importantly, the active exchange of research ideas and supporting each other in one way or another so that both of us carried out individual research with personal characteristics but also have joint products-this is one of them as an example. We can proudly say that many young people have benefited from the small but sharply focused symposium series, which allowed them to have one-to-one and face-toface discussion with the participants, especially the international speakers. Some of them have then established their research connections and personal friendship with the speakers. The impacts on them are apparent now as they are engaging independent research in their own labs of different universities both in China and abroad, and will last for a much longer time, probably their whole careers. The publication of this SI in 2014 is coincided with the retirement of Prof. Cheng from Nanjing University and he will be actively serving various roles to the university community and his School of the Environment. I think it is appropriate to honor this SI to him, to recognize his career in environmental research and education, and achievements in Environmental Biotechnology, which is his first book published in Chinese and influenced generations of students and educators. I myself have learnt a great deal from him through our enjoyable collaboration over the years on academic research and also personal interest.

As shown in the first seven papers of this SI, the theme of Contamination monitoring and ecosystem health includes investigations on nutrients, phytoplankton community and composition, metals and metalloids and polyaromatic hyadrocarbons of estuary system of Haihe River Basin, three lakes (namely Aobaopao, Baiyangdian and Delong), and Zhalong wetland, all in northern China, where the first oilfield was discovered. In the eight papers followed, the theme of Assessment of ecosystem risk 
focuses on similar pollutants in rivers (Lhasa and Wuyuer), lakes (Dongdahai, Huoshaohei, Keqin, Nashina, Qinkenpao, Wanghua, Xidahai, Xihulu, Xinhuahu), Zhalong wetland and cities (Beijing, Shanghai, Guangzhou and Xiamen) to yield information on ecosystem risk, which is very useful to research scientists and also for administrative decision-making (Fig. 1). Lakes around the first oil city Daqing in northern China were investigated to delineate the effect of oil drilling on contamination as this is a point source for the last 50 years. A set of another six papers on the theme of Toxicity testing and biomarkers presents findings on reproductive toxicity and genotoxicity of Yangtze River and Liuxihe reservoir, respectively; genotoxicity of both nitrobenzene and petrolume on Vicia faba, and water pollution in Taihu Lake using Euglena species as an indictor, and toxic response of carp (Cyprinus

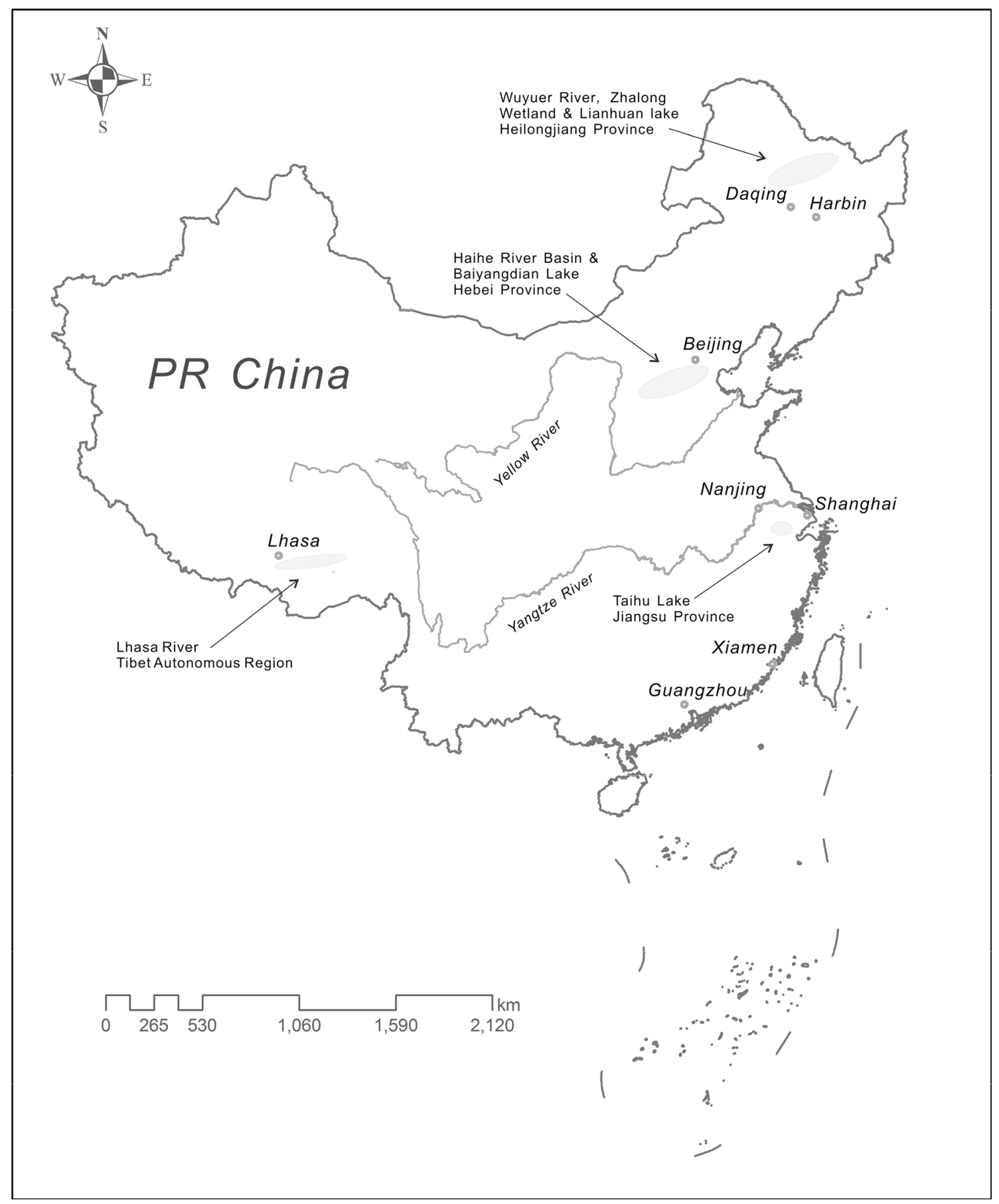

Fig. 1 A map of China with the research studying locations reported in this special issue 
carpio) to phthalate ester, reflecting the wide array of pollutants applicable to the current pollution problems in the country. On the theme of Pollution control, ecosystem responses and management, five papers present wastewater treatment and pollutant removal by wetland; water requirement for restoration of Haihe basin; and soil mesoand macro-arthropoda community in response to land use to address issue at various ecological levels. The final remaining six papers on the theme of Mechanisms of contaminant removal and control present phytoremediation of petroleum, and $\mathrm{Zn}$ and $\mathrm{Cu}$; sorption of Uranium and $\mathrm{Cr}(\mathrm{III})$ by bacterium and Chlorella miniata; and biosafety issue of genetic engineering plants on rhizosphere microbial community. This collection of papers keeps up the tradition of this symposium series on drinking water and geno-toxicity, expands the scope to northern China aquatic lakes and river basin as well as pollution in Lhasa to have a much wider view. It is clear that environmental contamination and cleaning up should be dealt with in case-by-case manner and different techniques should be used selectively based on the specific pollutant and conditions of the ecosystem to formulate the science-based approach. Because of this, nano-materials and abiotic process also have their role to play in solving the environmental problems (Xu et al. 2009; Luo et al. 2013). Similarly, phytoremediation is a subject where basic scientific investigation is still largely less recognized for their potential in pollutant removal, metals and metalloid or organics ( $\mathrm{Yu}$ and $\mathrm{Gu}$ 2006, 2009; $\mathrm{Yu}$ et al. 2008) and alleochemicals can also facilitate the inhibition of pollution-induce bloom of algae (Shao et al. 2013). Here we present some examples to illustrate to the world the nature of the environmental problems in the second largest economy of the world, the magnitude of them and the challenges facing our society of the global village, especially the emerging economies of currently developing countries because of the anthropogenic sources of pollution, high population density and related activities in these countries can result in pollution beyond the terrestrial landmass to coast and oceans (Cao et al. 2011, 2012; Li et al. 2011a, b).

Since the publication of Silent Spring in 1962, serious cases of oil spill, drinking water quality or contamination of food and beverages as well as plasticizers in toys and soft drinks, are still facing the public and the developing countries. In addition to the environmental pollutants of metals and polyaromatic hydrocarbons, pesticides and herbicides, endocrine-disrupting chemicals and pharmaceutical and personal care products are becoming more and more research focus for the current investigations. It is recognized that environmental problems are not a pure scientific question to human society there are fundamental socioeconomics basis for them to occur again and again in different countries and cultures. It must be true that both education and scientific research plus exchange of information to overcome some of the obstacles in communication so that our society can move forward in a concrete step each time in dealing with the environmental pollution problems and protect our living planet for future generations.

Conflict of interest The author declares that they have no conflict of interest.

\section{References}

Cao H, Li M, Dang H, Gu J-D (2011) Responses of aerobic and anaerobic ammonia/ammonium-oxidizing microorganisms to anthropogenic pollution in coastal marine environments. Methods Enzymol 496:35-62

Cao H, Hong Y, Li M, Gu J-D (2012) Community shift of ammoniaoxidizing bacteria along an anthropogenic pollution gradient from the Pearl River Delta to the South China Sea. Appl Microbiol Biotechnol 94:247-259

Cao H, Auguet J-C, Gu J-D (2013) Global ecological pattern of ammonia-oxidizing archaea. PLoS One 8:e52853. doi:10.1371/ journal.pone.0052853

Ford TE, Cheng S (2009) Special issue on source water risk control 18:643-646

Ford TE, Bass AL, Cheng S, Cherr GN, Cole B, Fairbairn E, Gu J-D, Halbrook RS, Löffler FE, Madsen EL, McGinn NA (2011) EHPC 2010: sharing knowledge on environmental health for risk mitigation. Ecotoxicology 20:937-939

Gu J-D, Wang Y (2012) Environmental feedback: lessons from pollution problems in China. Ecotoxicology 21:1583-1584

Gu J-D, Wang Y (2013) A new era for geomicrobial ecotoxicology in environmental science research. Int Biodeterior Biodegradation $76: 1-2$

Han X, Li Y-L, Gu J-D (2011) Oxidation of As(III) by $\mathrm{MnO}_{2}$ in the absence and presence of $\mathrm{Fe}(\mathrm{II})$ under acidic conditions. Geochim Cosmochim Acta 75:368-379

Li M, Cao H, Hong Y, Gu J-D (2011a) Spatial distribution and abundance of ammonia-oxidizing archaea (AOA) and ammoniaoxidizing bacteria (AOB) in mangrove sediments. Appl Microbiol Biotechnol 89:1243-1254

Li M, Ford T, Li X-Y, Gu J-D (2011b) Cytochrome $c d 1$-containing nitrite reductase encoding gene nirS as a new functional biomarker for detection of anaerobic ammonium oxidizing (Anammox) bacteria. Environ Sci Technol 45:3547-3553

Luo S, Luo S, Qin P, Shao J, Peng L, Zeng Q, Gu J-D (2013) Synthesis of reactive nanoscale zero valent iron using rectorite supports and its application for Orange II removal. Chem Eng J 223:1-7

Shao J, Li R, Lepo JE, Gu J-D (2013) Potential for control of cyanobacterial blooms using bioactive substances: problems and prospects. J Environ Manag 125:149-155

Shen P, Zhou H, Gu J-D (2010) Patterns of polychaete communities in relation to environmental perturbations in a subtropical wetland of Hong Kong. J Mar Biol Assoc UK 90:923-932

Wu B, Cheng S, Li Y, Kong J, Zhao D, Zhang Y, Zhang X (2009) Transcriptional toxicity of the Yangtze River source of drinking water on mouse (Mus musculus). Ecotoxicology 18:715-721

Xu X-R, Li S-X, Li X-Y, Gu J-D, Chen F, Li X-Z, Li H-B (2009) Degradation of $n$-butyl phthalate using $\mathrm{TiO}_{2} / \mathrm{UV}$. J Hazard Mater 164:527-532

Yu X, Gu J-D (2006) Uptake, metabolism and toxicity of methyl tertbutyl ether (MTBE) in weeping willows. J Hazard Mater B137:1417-1423 
Yu X-Z, Gu J-D (2009) Uptake, accumulation and metabolic response of ferricyanide in weeping willows. J Environ Monitor $11: 145-152$

Yu X, Gu J-D, Xing L-Q (2008) Differences in uptake and translocation of hexavalent and trivalent chromium by two species of willows. Ecotoxicology 17:747-755

Zhao D, Wu B, Cui Y, Zhang Y, Zhang X, Li W, Cheng S (2009) Toxicity of the Yangtze River source of drinking water on reproductive system of male mice (Mus musculus). Ecotoxicology 18:729-735

Zhao Z, Zhuang Y-X, Gu J-D (2012a) Abundance, composition and vertical distribution of polycyclic aromatic hydrocarbons in sediments of the Mai Po Inner Deep Bay of Hong Kong. Ecotoxicology 21:1734-1742

Zhao Z-Y, Chu Y-L, Gu J-D (2012b) Distribution and sources of polycyclic aromatic hydrocarbons in sediments of the Mai Po Inner Deep Bay Ramsar Site in Hong Kong. Ecotoxicology 21:1743-1752

Zhao Y, Gu J-D, Zhan X (2013) Recent advances in water resource management and pollution control: with special focus on China. Environ Eng Manag J 12:887-888 